\title{
APPLICATION AND ANALYSIS OF PSYCHOLOGICAL SCALE BASED ON GENETIC ALGORITHM IN SPORTS PSYCHOLOGY
}

\section{APLICACIÓN Y ANÁLISIS DE LA ESCALA PSICOLÓGICA BASADA EN ALGORITMOS GENÉTICOS EN PSICOLOGÍADEPORTIVA}

\section{Yi Zhang' (ID) \\ (Public Health Education)}

1. Nanjing University of Science and Technology, Jiangsu Nanjing, 210094, China.

\section{Correspondence:}

Jiangsu Nanjing, 210094, China. td0961njup5179@126.com

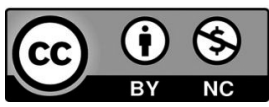

\begin{abstract}
With the rapid development and application of computer technology, the study of sports psychology is one of the major research tasks in current universities. The psychological scales need to be converted according to current computer technologies. Because the old-fashioned methods cannot meet the increasing demand, application of psychometric scale based on genetic algorithm in sports psychology is applied to construct the research model. Analytic hierarchy process is used to compare the weights of indicators. In the research mode of sports psychology, the auxiliary ability of college psychological scale is applied to improve the application of sports psychology ability.
\end{abstract}

Keywords: Algorithm; Psychological scale; Psychology, Sports.

\section{RESUMO}

Com o rápido desenvolvimento e aplicação da tecnologia da computação, o estudo da psicologia esportiva é uma das principais tarefas de pesquisa nas universidades atuais. As escalas psicológicas precisam ser convertidas de acordo com as tecnologias da informação atuais. Tendo em vista que os métodos antigos não satisfazem a demanda crescente, aplica-se a escala psicométrica baseada no algoritmo genético no campo da psicologia esportiva para construir o modelo de pesquisa. Utiliza-se o processo de hierarquia analítica para comparar os pesos dos indicadores. No modo de pesquisa da psicologia esportiva, aplica-se a capacidade auxiliar da escala psicológica para melhorar a aplicação da psicologia esportiva.

Descritores: Algoritmo; Escala psicológica; Psicologia do Esporte.

\section{RESUMEN}

Con el rápido desarrollo y la aplicación de la tecnología de la computación, el estudio de la psicología deportiva es una de las principales tareas de investigación en las universidades actuales. Las escalas psicológicas precisan ser convertidas de acuerdo con las tecnologías de la información actuales. Teniendo en vista que los métodos antiguos no satisfacen la demanda creciente, se aplica la escala psicométrica basada en el algoritmo genético en el campo de la psicología deportiva para construir el modelo de investigación. Se utiliza el proceso de jerarquía analítica para comparar los pesos de los indicadores. En el modo de investigación de la psicología deportiva, se aplica la capacidad auxiliar de la escala psicológica para mejorar la aplicación de la psicología deportiva.

Descriptores: Algoritmo; Escala psicológica; Psicología del Deporte.

\section{INTRODUCTION}

With the rapid development of China's socialist modernization, the form and scale of sports psychology in China are constantly expanding.' At present, the quality of sports psychology in colleges and universities has attracted great attention from the state and society, especially in recent years, the country's emphasis on sports has increased. ${ }^{2}$ Now, the quality of sports psychology classes in colleges and universities has become a necessary task. In this study, from the actual situation of the sports psychology class, according to the training and rules of the sports psychology class, the principle of sports psychology and the course of sports psychology in Colleges and universities are combined. Mastering the characteristics through psychological changes in the process. ${ }^{3}$ On this basis, the blindness of the pair is reduced and the overall development of students is promoted. Based on the study of psychological scale, the quality of current sports psychology in colleges and universities in China is improved. The students' psychological phenomena during sports psychology exercise are observed, thus providing data dependence when improving the psychology of sports psychology. Only by combining these evaluations can we make a comprehensive analysis. It is of great significance to improve the quality of sports psychology. Through the application research of psychological scale in the sports psychology of colleges and universities in the background of computer, the sports psychology teachers can change their own methods and methods, and continuously improve the education, so that sports psychology can develop in a better direction. ${ }^{4}$ 


\section{STATE OF THE ART}

Sports psychology is a product that combines physical exercise with psychology. The factors of sports are important, but the psychological effects cannot be ignored. ${ }^{5}$ Based on genetic algorithm, the relationship between sports psychology and psychological scale is studied in two aspects. The study of genetic algorithms originated in biology and is proposed based on the genetic laws of biology. In the course of this study, a great deal of relevant literature was referenced. Through the combination of cross-disciplines, the establishment of an exercise assistance system is more in line with the requirements of sports psychology in colleges and universities at this stage. The operation of genetic algorithm is mainly an optimal process, which is the process of integrating a large number of data collection into a series of processing operations and selecting the best results from it. The research of genetic algorithm in China starts late, and there are still some defects in the research of genetic algorithm. In the United States, the research on genetic algorithm is the earliest. After many years of research, its algorithm technology has also been continuously improved. Genetic algorithm is widely used in the field of intelligent electronics, which is an excellent algorithm to select large amounts of data. The guidance and research of the genetic algorithm on the mental scale action in the teaching of sports psychology can be better combined with the sports psychology and psychological scale action after the selective treatment.

\section{RESEARCH ON DATA ANALYSIS OF PSYCHOLOGICAL SCALE IN SPORTS PSYCHOLOGY BASED ON GENETIC ALGORITHM}

The study of psychological scale in the field of kinematics is a multi-objective computational research problem. For the study of multi-objective optimization problems, in fact, genetic algorithms have a unique form of calculation to study and analyze this part of the problem. The research is mainly aimed at the multi-objective optimization problem. In fact, in the computational study of genetic algorithms, it has been found that the criteria for determining the quality of a population in a genetic algorithm can be compared using the Pareto-dominant relationship. In the use of genetic algorithm, the definition of Pareto dominance relation is an essential process, which directly affects the computational stability of the whole genetic algorithm. According to the analysis of the reliability of the interval dominant, the lower bound of the interval-dominated credibility is defined. The Pareto dominance relation based on the lower bound and its corresponding Pareto optimal solution set are also given. Then, the dominant relation is replaced by the traditional Pareto dominance relation, and the NSGA-ll's fast non dominated solution ranking method is modified. A new genetic algorithm for solving multi-objective optimization problems with interval parameters is developed, and the performance of the algorithm is theoretically analyzed.

Before the calculation and research of genetic algorithm, it is necessary to compare the calculation concept of genetic algorithm with the concept of mathematics and the concept of genetics to facilitate the optimization of the calculation formula. The comparison is shown in Table 1 below.

The key point of multi-objective optimization lies in the simultaneous optimization of multiple objectives. There are often some computational conflicts in the study of multi-objective simultaneous computation. The purpose of the research is to make all the targets as close to the optimal solution as possible, to ensure the correctness of the calculation target in the algorithm, and to improve the calculation accuracy of the algorithm. In this regard, the traditional calculation of the genetic algorithm has been carefully studied and calculated and the computational formulae and calculation process of the traditional genetic algorithm have been calculated and analyzed. The following is an optimization analysis of the calculation formula of the multi-objective optimization genetic algorithm.
Table 1. Computational Concepts of Genetic Algorithms and Comparison of Mathematical Concepts and Genetic Concepts.

\begin{tabular}{c|c|c|c}
\hline Numbering & Genetics & Genetic algorithm & Mathematics \\
\hline 1 & individual & $\begin{array}{c}\text { The object structure } \\
\text { to be processed }\end{array}$ & Feasible solution \\
\hline 2 & group & Individual collection & $\begin{array}{c}\text { Selected feasible } \\
\text { solutions }\end{array}$ \\
\hline 3 & chromosome & Individual manifestation & Selected encoding \\
\hline 5 & gene & Chromosomes & $\begin{array}{c}\text { The position of the } \\
\text { element in the encoding }\end{array}$ \\
\hline 6 & Gene position & $\begin{array}{c}\text { The position of a gene } \\
\text { in a chromosome }\end{array}$ & $\begin{array}{c}\text { Fitness function } \\
\text { Individual adaptation } \\
\text { function value }\end{array}$ \\
\hline 7 & select & $\begin{array}{c}\text { Outstanding Individuals } \\
\text { in the Population }\end{array}$ & $\begin{array}{c}\text { Keep a large } \\
\text { feasible solution }\end{array}$ \\
\hline
\end{tabular}

Multi-objective optimization problems are also called multi-criteria optimization problems. The multi-objective maximization problem is considered as follows:

$$
\max f(x)=\left(f_{1}(x), f_{2}(x), \cdots f_{n}(x)\right)
$$

Where: $\mathrm{x}$ is an $\mathrm{n}$-dimensional decision variable, $\mathrm{S}$ is the decision space of $x$, and $m$ is the number of objective functions.

Thus, each evolved individual $x$ in the population has two attributes: Pareto ordinal rank $\left(x_{i}\right)$ and crowding distance $\left(x_{i}\right)$. According to these two attributes, the total order relationship can be defined as: $x_{i}, x_{j}$ is 2 different evolutionary individuals. If $x_{i}>x_{j}$, only rank $\left(x_{i}\right) \leq \operatorname{rank}\left(x_{j}\right)$, then $\operatorname{distance}\left(x_{i}\right) \geq \operatorname{distance}\left(x_{j}\right)$.

ZDTI is a test problem with continuous real Pareto frontier. The description is as shown in Equation 2:

\begin{tabular}{l}
$\operatorname{minf}(x)=\left(f_{1}(x), f_{2}(x)\right)$ \\
Where : $f_{1}(x)=x_{1}$ \\
$f_{2}(x)=g(x)\left(1-\sqrt{f_{1}(x) / g(x)}\right)$ \\
$g(x)=1+9 \sum_{i=1}^{m} x_{i} /(m-1)$ \\
\hline
\end{tabular}

Then:

$$
\operatorname{minf}_{m}(x)=\left(1+g\left(x_{m}\right)\right) \sin \left(x_{1} \pi / 2\right)
$$

The image of the function changes as shown in Figure 1.

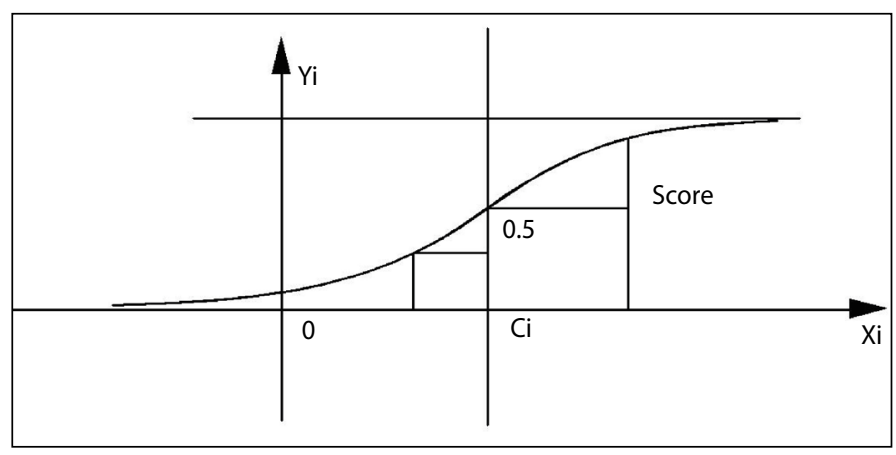

Figure 1. Image change of function. 
Similarly, Vector $x_{m}$ contains $\mathrm{k}=\mathrm{n}-\mathrm{m}+1$ variables. The true Pareto front of this problem corresponds to all $x_{i}^{\prime}$ s of $x_{m}$ being 0.5 and the objective function value satisfying $\sum_{i=1}^{m}\left(f_{i}\right)^{2}=1$.

Without losing generality, the following interval parameter multi-objective maximization problem is considered.

$$
\max f(x, c)=\left(f_{1}(x, c), f_{2}(x, c) \cdots f_{m}(x, c)\right)
$$

Therefore, the objective function values are all intervals and are written as:

$$
f_{i}(x, c)=\left[f_{j}(x, c), \overline{f_{j}}(x, c)\right]
$$

And the super volume of the calculation problem is as follows:

$H(X)=\lfloor\underline{H(X), \overline{H(X)}\rfloor} \quad$ (6)

In this way, the calculation formulas and optimization studies of the genetic algorithms used for calculations have been established. In fact, the analysis of psychological scales is also a multi-objective calculation. After all, the key factors studied in the psychological scale are not one or two. In general, there will be a variety of parameter analysis and analysis in the calculation. The use of this multi-objective optimization genetic algorithm for computational analysis is more relevant to calculations. By using this genetic algorithm for computational research, the application of psychological scales in the field of sports psychology can be more accurate. The calculation of the genetic algorithm used is an optimized algorithm, which is mainly aimed at the reasonable optimization of the calculation content, so that the calculation of the algorithm is closer.

\section{RESULT ANALYSIS AND DISCUSSION}

After the genetic algorithm optimization research, the computational performance of its calculation method can be studied. The first thing to study is the change in the computational performance of the genetic algorithm when $\gamma$ changes. The study is for changes in the computational performance of three cases where $\gamma$ is $0.6 / 0.8 / 1$, and the changes are analyzed using the form of Figure 2 below.

A study of Figure 2 above shows that for the same $\gamma$, the increase in evolutionary algebra directly affects the increase of $\mathrm{H}$ measures. Also, as $\gamma$

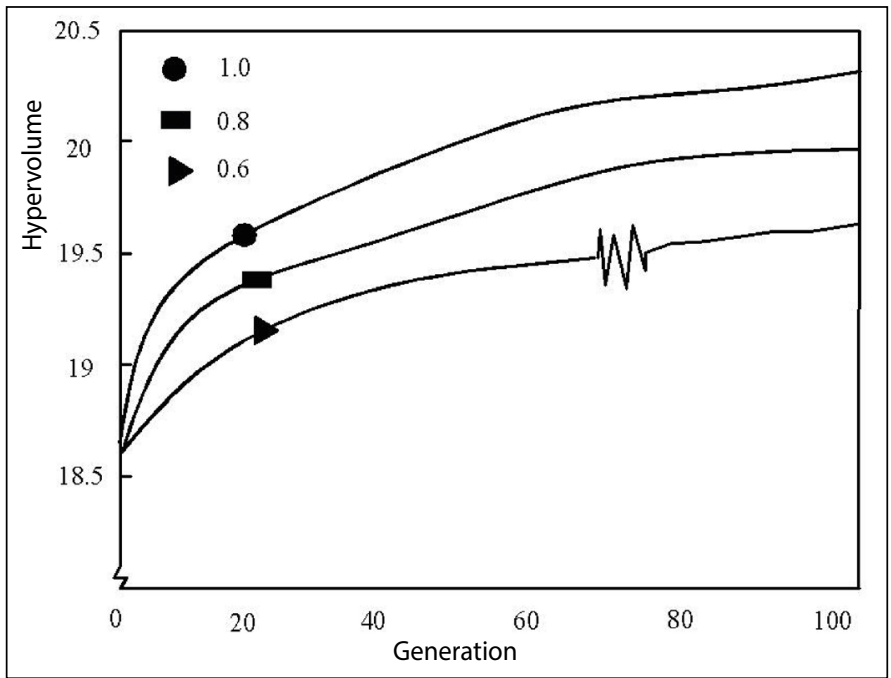

Figure 2. The change of computing performance of genetic algorithm under different parameters. becomes larger, the H measure increases faster. This shows that the establishment of this new genetic algorithm calculation form can accurately calculate the data of the psychological scale. And with the increase of $\gamma$, the degree of linearity exhibited by the data of the psychological scale is better. In fact, when $\gamma$ is 0.6 and the calculation result of the genetic algorithm is about 100 in the evolution algebra, the genetic algorithm has a certain zigzag change in the $\mathrm{H}$ test. This change shows that when $\gamma$ is 0.6 , the algorithm is difficult to control the computational stability of the entire calculation process. So, a conclusion has been found by testing that the closer the $y$ value is to 1 , the better the computing performance of the algorithm. When $\gamma$ is 1, the computational stability of the algorithm is the best.

After studying the change of the $H$ test value, the $T$ test value needs to be calculated and studied. For the calculation of $T$ test values, five groups of test experiments were used for the study. The value of $\gamma$ is still used as an independent variable, and the value of $\gamma$ is $0.5 / 0.6 / 0.8 / 1$. The test results are shown in Table 2 as shown below.

Analyzing the data in the above table is available: In the study of the same problem, the change in $\gamma$ is proportional to the size of the $Z$ test value. At the same time as $\gamma$ increases, the optimal solution of the algorithm is the most. The increase in the optimal solution represents an overall increase in the computational accuracy of the algorithm, which also explains the effect of the change in the $\gamma$ value on the overall computational accuracy of the genetic algorithm. A conclusion can be drawn from the comparison of the measured values in $\mathrm{H}$ above that the accuracy of the algorithm is directly related to the size of the $\gamma$ value. And the greater the $\gamma$ value used by the algorithm, the higher the calculation accuracy of the algorithm. At the same time, because the test is calculated using computers, the calculation time of the algorithm usually increases with the complexity of the calculation parameters. However, the increase in the $\gamma$ value do not cause the calculation time of the algorithm to increase. Based on the above findings, it is found that in the computational study of sports psychology, when the value of $\gamma$ is 1 , the accuracy of mental scale is the best.

In addition, the comparison between the traditional genetic algorithm and the optimized genetic algorithm is also studied. This comparison of computational performance uses computational time and computational accuracy, and computational analysis of the resulting computational data is performed in accordance with certain weights. Through the comparison of this calculation, it is proved that the optimization of the genetic algorithm is successful. A contrast diagram for computational performance is shown in Figure 3 below.

The analysis of the data in the above figure shows that as the calculation parameters increase, the computational performance of the algorithm changes to some extent. Firstly, the traditional genetic algorithm is analyzed and studied. The computational performance of traditional algorithms decreases rapidly with the increase of calculation parameters, which shows that traditional algorithms are not suitable for calculation. For the optimized genetic algorithm, the computational power of the algorithm will not decrease with the increase of computational performance within the scope of the study. Through this computational study, it is shown that the calculations in the application of genetic algorithms in the field of psychometrics and sports psychology can be performed accurately and stably.

Table 2. T parameter calculation performance change table under different parameters of genetic algorithm.

\begin{tabular}{c|c|c|c|c}
\hline Calculation group & $\mathbf{0 . 5}$ & $\mathbf{0 . 6}$ & $\mathbf{0 . 8}$ & $\mathbf{1}$ \\
\hline Group1 & 8.00 & 10.06 & 15.70 & 16.84 \\
\hline Group2 & 5.00 & 11.04 & 11.60 & 19.52 \\
\hline Group3 & 5.13 & 9.84 & 11.04 & 14.10 \\
\hline Group4 & 4.80 & 11.62 & 8.06 & 17.54 \\
\hline Group5 & 4.78 & 17.40 & 15.61 & 17.57 \\
\hline
\end{tabular}




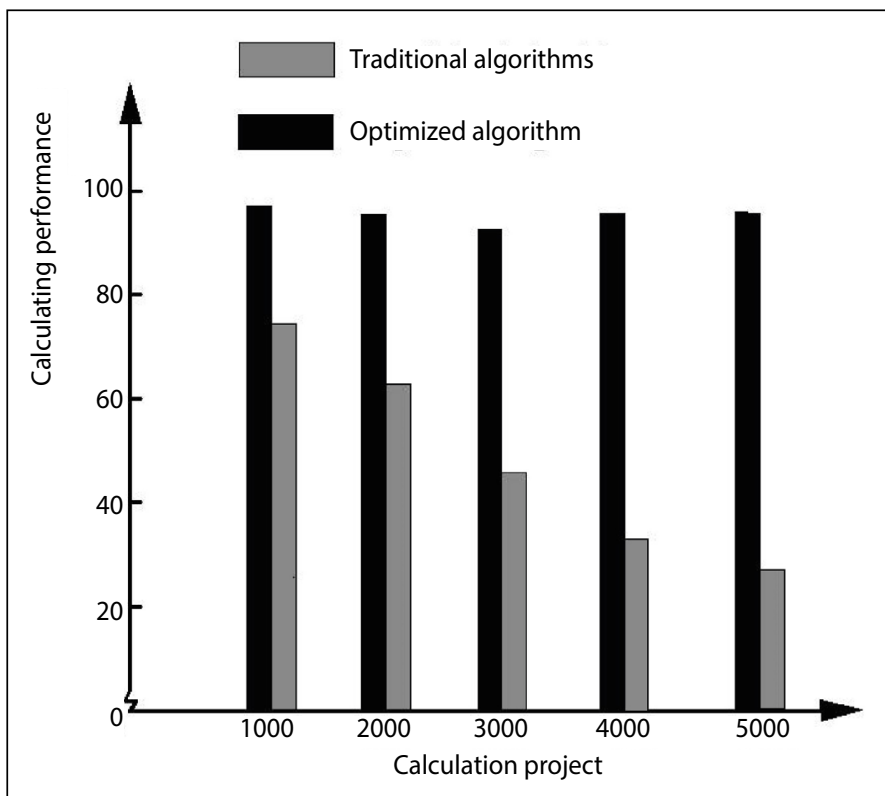

Figure 3. Comparing the performance of the two genetic algorithms.

\section{CONCLUSION}

The psychological scale has important research significance in the calculation and analysis of psychology. In the study of the study of sports psychology in the study, for the data analysis of psychological scale, the calculation of multi-objective optimization genetic algorithm is used. In addition, the optimization of multi-objective optimization genetic algorithm is studied, and the optimization of genetic algorithm is improved. Through the test of genetic algorithm, it is found that the computing power of the multi-objective optimization genetic algorithm is positively related to the value of $\gamma$. Therefore, the multi-objective genetic algorithm is the most accurate when $\gamma$ is 1 . In addition, a comparative study is made between the traditional genetic algorithm and the optimized genetic algorithm. Through the study, it is found that the computational power of the genetic algorithm used in the calculation within the scope of the study is very high, and the computational requirements in the data analysis of the psychological scale are achieved. In the future, the calculation requirements for the data analysis of the psychological scale will also perform in-depth optimization analysis of the calculation of the genetic algorithm.

The author declare no potential conflict of interest related to this article

AUTHORS' CONTRIBUTIONS: The author has completed the writing of the article or the critical review of its knowledge content. This paper can be used as the final draft of the manuscript. Every author has made an important contribution to this manuscript. Yi Zhang: writing and execution.

\section{REFERENCES}

1. Gai K, Qiu M, Zhao H. Cost-aware multimedia data allocation for heterogeneous memory using genetic algorithm in cloud computing. IEEE Transactions on Cloud Computing. 2016;PP(99):1-1.

2. Do NA, Nielsen IE, Chen G, Nielsen P. A simulation-based genetic algorithm approach for reducing emissions from import container pick-up operation at container terminal. Annals of Operations Research. 2016;242(2):285-301

3. Dou R, Zong C, Li M. An interactive genetic algorithm with the interval arithmetic based on hesitation and its application to achieve customer collaborative product configuration design. Applied Soft Computing. 2016;38(C):384-94
4. Yoshitomi Y, Ikenoue H, Takeba T, Tomita S. Genetic algorithm in uncertain environments for solving stochastic programming problem. Journal of the Operations Research Society of Japan. 2017;43(2):266-90

5. Ardjmand E, Young WA, Weckman GR, Bajgiran OS, Aminipour B, Park N, et al. Applying genetic algorithm to a new bi-objective stochastic model for transportation, location, and allocation of hazardous materials. Expert Systems with Applications. 2016;51(C):49-58. 